\title{
NOTAS SOBRE O ENSINO DE CLÁSSICOS LITERÁRIOS PORTUGUESES
}

\author{
Maria do Socorro Fernandes de Carvalho \\ mariafern@uol.com.br
}

Uma reflexão sobre o ensino de literatura clássica no sistema escolar pode revelar oportunidades de revisar alguns conhecidos problemas vivenciados pelo professor de literatura no Brasil. Sabese do desinteresse institucional e, ao que parece por consequência, também por parte do alunado, em relação à matéria da literatura, seja ela brasileira ou "universal", quando apresentada em sala de aula no ensino formal. Embora depoimentos pessoais de jovens e adultos saídos dos quadros escolares registrem, em sua maioria, certa simpatia pelos livros da disciplina de literatura, os quais trazem aquela conhecida dose de amenidade ou fantasia face às agruras experimentadas nos estudos forçados de física, química ou matemática, embora esse alento, eu dizia, comenta-se o progressivo esvaziamento dos estudos literários nos currículos escolares de hoje em dia e o alheamento dos alunos diante do patrimônio literário. Contrariamente ao efeito esperado, também é verdade que, segundo a experiência de educadores, a disciplina escolar gera no aluno, por vezes, uma notória aversão pela literatura. Ou seja, o que era para unir, acaba por separar.

Dado que este debate envolve toda série de fatores - educacionais, mercadológicos, sociológicos evários outros, destacarei apenas umaspecto desse universo complexo e labiríntico: a defesa do estudo do cânone das letras constituído em tempos históricos diversos de nossa atualidade. Pela certeza de que constitui uma possibilidade de conhecimento privilegiado 
de valores, gêneros, lugares, signos e saberes desses outros tempos pelo trabalhoartístico coma linguagem, a chamada "literatura clássica em língua portuguesa" apresenta ao estudante fecunda possibilidade de experiência de leitura das tradições brasileira, européia e ocidental. Esse é o lado bom da história, o qual deveria ser apropriado pelos estudos literários do ensino básico. Com efeito, o conhecimento das letras portuguesas dos séculos XVI, XVII e meados do século XVIII significa ao estudante brasileiro a possibilidade de inserção no mundo europeu totalmente diferenciado de nossa atualidade e até mesmo de nossa modernidade literária. Para estudantes brasileiros, trata-se de conhecer um mundoanteriorà formação de nosso sentido de nacionalidade literária e mesmo de nacionalidade civil. Se tomarmos um conceito de tradição, segundo João Adolfo Hansen, como "um valor de uso, entre outros, que determinado material passado passa a ter num determinado presente que dele se apropria e o transforma imprimindo-lhe determinada deformação", teremos na matéria da literatura portuguesa, melhor, escrita em língua portuguesa, um leque abrangente de saberes e informações, bastantes edificantes ao estudante lusófono do Brasil contemporâneo.

O cânone é um lugar onde transitam várias tradições. Apesar de, aos olhos de algumas pedagogias hodiernas, apresentar um aspecto "passadista" a defesa de seu ensino, é inegável que, sendo o cânone um lugar prestigiado da memória literária, a defesa de seu estudo no ensino básico tem de vir acompanhado da prescrição de apropriação pela escola de nossos dias. Embora todos saibam que, do ponto de vista pragmático, estudar o cânone literário significa ler e interpretar livros de antemão escolhidos pelas instituições escolares, não é desconhecido que "todo cânone implica uma seleção valorativa que se impõe com autoridade e aspira a modelar de maneira durável a compreensão da herança literária”². O que implica igualmente rejeições de vários setores: do domínio de algumas vertentes da pedagogia, da juventude naturalmente reativa do aluno virtual do ensino básico, de algumas gerações de professores brasileiros que identificam tradição a conservadorismo político ou dominação pelas ideologias, enfim, o cânone aparece revestido de vários signos que lhes trazem vantagens e alguns efetivos preconceitos.

${ }^{1}$ Cf. João A. Hansen. "Autor". In: Palavras da crítica: tendências e conceitos no estudo da literatura. Org. José Luís Jobim. Rio de Janeiro. Editora Imago, 1992.

${ }^{2}$ Gustavo Guerrero. Poétique et poésie lyrique: essai sur la formation d'un genre. Trad. Anne-Joëlle Stéphan et l'auteur. Paris: Éditions du Seuil, 2000, p. 37. (Tradução livre.) 
O certo é que, apesar de haver certa dificuldade no estudo das letras mais distantes de nosso tempo, vivenciada por parte dos professores e pesquisadores em razão das diferenças de linguagem, moral, composição sociocultural e sensibilidade, de modo geral, e do hodierno desprestígio dessa matéria na historiografia literária dos séculos XX e XXI, existe, por outro lado, corrente a ideia de que tal estudo pode ser realizado nos vários níveis escolares definidos pelo sistema educacional brasileiro. Difícil é convencer os professores e os alunos de que estudar sermões, poesias, cartas, diálogos, tratados ou sonetos religiosos pode ser tão instigante quanto, entre jovens, ler poesia concreta ou poemas de Álvaro de Campos.

Embora os parâmetros educacionais em vigência tenham desprestigiado o estudo da literatura portuguesa em sua unidade disciplinar, minando paulatinamente essa matéria dos currículos obrigatórios e, por consequência, a abertura desse conhecimento que presentemente defendo, o estudo das letras escritas em língua portuguesa sob o "sistema retórico classicista" (por assim dizer) continua a oferecer, nos nichos sobreviventes, lugar de aquisição, debate e atualização de várias tradições literárias, desde a poesia de imitação dos grandes autores das latinidades e antiguidades gregas, até os versos convencionais da "medida velha", na melhor tradição ibérico-portuguesa, para ficar apenas com a ilustração dessas principais convenções poéticas. A língua portuguesa pode não constituir a nação lingüística idealizada pelos defensores da manutenção da unidade do ensino das duas literaturas numa mesma disciplina, como ocorreu no início do século XX no Brasil, e perdurou sob o argumento de uma suposta nacionalidade lingüística, segundo o depoimento de estudantes de então, por toda a década de 1950, alcançando até o início da década seguinte. Todavia, o estudo dessas letras, convencionalmente cingidas na rubrica de "literatura portuguesa", continua a prover ao seu estudante experiências de linguagem especiais que só a arte da palavra pode oferecer de forma particular e insubstituível. Se não é mais possível pensar numa suposta "nação da língua portuguesa", pois esta se mostra diferenciada tanto nos seus muito diversificados usos no Brasil, em Portugal e nos países africanos lusófonos, quanto nas especificidades dos códigos literários de cada país, e - ademais, os estudos literários constituem progressivamente esmiuçada especificidade para ser instrumento único de análise dos signos e valores literários de produções artísticas diversas, mesmo escritas por uma língua comum - se não é possível tal unidade disciplinar, como dizia, é muito visível a possibilidade e os ganhos que seu estudo específico traz ao leitor que se vê ingressar num universo literal ingente, multiforme e sedutor dos textos clássicos escritos em nossa língua; significa enfim ter acesso a certas tradições. 
Acredito que o estudo das letras em língua portuguesa escritas entre os séculos XVI, XVII e XVIII, tomadas como "classicistas", para além de específico no sentido disciplinar, deve manter sua especificidade instrumental teórica, pois, como é sabido, uma das características fundantes das letras classicistas é sua diferenciação em relação ao sistema literário subseqüente, a modernidade artística, que aportou um sistema de representação totalmente diferenciado dos modelos anteriores. No lugar da imitação de modelos tem-se uma série de novos valores, dentre eles o da originalidade: trazer o novo deixou de ser tomado como índice de incapacidade de inserção numa tradição verbal, como era antes visto, para tornar-se signo de excelência da "imaginação criadora", núcleo da poética da modernidade nas letras ocidentais, difundidas primeiramente pelo pensamento romântico e assimilado por toda a produção literária posterior - na Europa e no Novo Mundo - até pode-se dizer nossos dias, guardadas as diferenças de tempo e lugar. Outros valores são visivelmente diferençáveis e não é necessário aqui refletir sobre suas naturezas, bastando elencá-los para que suas constituições diversas apareçam: a noção de modelo cede ao valor da originalidade, a noção de autoridade é minada pela normatização dos direitos autorais, a noção de obra recebe os matizes de mercadoria, a subjetividade anula a aplicação de lugares-comuns, a retórica como sistema que instrui e ordena os usos da linguagem decai em nome do surgimento da literatura, em si mesma moderna, dentre outros importantes aspectos. Portanto, o ensino dessas letras deve estar atento e adaptado a tais condicionamentos históricos. Sua prática deve considerar sempre, do ponto de vista do aluno, a possibilidade da construção de conhecimentos do discurso literário pela busca de verossímeis textuais. Assim, é pela possibilidade de compreensão do fazer, leitura, circulação e por vezes rejeição de tradições letradas que se constroem em sala de aula verossímeis possíveis de leitura de poemas, cartas, autos, diálogos, tratados, sátiras ou qualquer gênero discursivo hoje tomado como "clássico". Sem a ilusão de aportar ao estudante, pela leitura de obras, certa reprodução da "realidade" de um tempo, defendo a leitura conjunta, professor e aluno, pela busca de construção de um (ou de vários) sentidos possíveis e verossímeis ao texto, atendendo ao saber de suas muito específicas condições de produção e alcance no seu tempo e lugar históricos ${ }^{3}$. Isto porque tal alcance histórico depende, sabe-se igualmente, de linhas de pensamentos constituídas por valores, hierarquias, costumes, representações e signos somente operáveis e atuantes naquele determinado momento e lugar históricos. 
Este fator originário da teoria da literatura deriva contudo ação didática que interfere no cotidiano dos cursos de literatura de língua portuguesa. Compondo portanto certo "conteúdo" historicamente anterior à modelagem da autonomia da literatura brasileira em relação à portuguesa, dado que nascemos literariamente quando o Ocidente formulava e praticava letras e artes já modernas, sobretudo pela divulgação operada pela prosa e poesia românticas, o ensino das letras clássicas em língua portuguesa no Brasil estaria "isento" ou "neutralizado" em relação a uma das razões mais profícuas de reflexão e motivo de reincidentes objeções na discussão sobre a manutenção ou não da autonomia da disciplina de literatura portuguesa no sistema educacional nacional: a independência de nossa literatura, própria e a partir dessa compreensão madura como disciplina única nos programas. Anterior à problemática brasileira de afirmação de sua soberania cultural, um dos principais fatores de afirmação da separação entre as matérias portuguesa e brasileira nos vários níveis escolares, segundo reflexão feita por Haquira Osakabe sobre o ensino de literatura portuguesa no Brasil, os estudos clássicos em língua portuguesa tendem a ficar alijados dos interesses nos programas e currículos constituídos no decorrer do século $\mathrm{XX}$, até hoje. Com isso, surgem argumentos como os de que a literatura portuguesa de outros tempos não serve aos interesses e sensibilidades de nossos estudantes, mais voltados e abertos ao estudo de outras ordens discursivas, mais próximas de nós ${ }^{4}$.

Grande desafio didático configura-se, portanto, pela capacidade do professor de, mantido primeiramente seu espaço disciplinar, apresentar ao estudante-leitor um universo discursivo de composição com dimensões estrelares, rico e salutar como os de nossos clássicos autores, de modo que a ele seja possível buscar sentidos de leituras verossímeis na historicidade dos muito variados gêneros (epigramas, voltas, cantigas, éclogas, epístolas, trovas, elegias, epopéias, tragédias, sermões, sonetos, canções, vilancetes, décimas, sátiras, discursos heróicos, comédias, redondilhas, tercetos, discursos acadêmicos, oitavas e muitos, muitos outros subgêneros poéticos e prosaicos de larga produção em Portugal e no Brasil neste período). É precisamente pela diversidade em relação ao grande sistema da modernidade das artes (e portanto das literaturas) que o texto classicista deve ser trazido para a sala de aula. É precisamente pelo conhecimento, debate, refutação ou apreciação de suas características genéricas próprias que devemos aportar as letras dos séculos XVI, XVII e XVIII ibéricos, europeus, portugueses e por isso brasileiros.

${ }^{4}$ Cf. Haquira Osakabe, in: Voz lusíada, revista da Academia lusíada de ciências, letras e artes. $\mathrm{O}$ ensino de literatura portuguesa, n. 18, 2002, passim. 


\section{2 - Remate de Males 34.2 \\ REFERÊNCIAS BIBLIOGRÁFICAS}

GUERRERO, Gustavo. Poétique et poésie lyrique: essai sur la formation d'un genre. Trad. Anne-Joëlle Stéphan et l'auteur. Paris: Éditions du Seuil, 2000.

HANSEN, João Adolfo. "Autor". In: Palavras da crítica: tendências e conceitos no estudo da literatura. Org. José Luís Jobim. Rio de Janeiro. Editora Imago, 1992.

LOURENÇO, Eduardo. A Nau de Ícaro e Imagem e miragem da lusofonia, São Paulo: Companhia das Letras, 2001.

Vários Autores. Literatura portuguesa: história, memória e perspectivas, São Paulo: Ed. Alameda, 2007.

VERNEY, Luís António.Verdadeiro método de estudar: cartas sobre retórica e poética. (1746). Lisboa: Presença, 1991.

OSAKABE, Haquira. In: Voz lusíada, revista da Academia lusíada de ciências, letras e artes. O ensino de literatura portuguesa, n. 18, 2002. 